\title{
FINANCING OF THE HEALTH PROMOTION AND PREVENTION ACTIVITIES FOR CHILD AND MATERNAL HEALTH OF GENERAL PRACTITIONERS PRACTICES IN BULGARIA
}

\author{
A. Zdraveska ${ }^{1}$, B. Parashkevova ${ }^{1}$, N. Penev ${ }^{2}$, I. Nencheva ${ }^{2}$, S. Simeonov ${ }^{3}$, J. Marinova $^{1}$ \\ ${ }^{1}$ Department of Social Medicine and Health Care Management, Medical Faculty, Trakia University, \\ Stara Zagora, Bulgaria \\ ${ }^{2}$ Faculty of Economics, Trakia University, Stara Zagora, Bulgaria \\ ${ }^{3}$ Regional Branch of National Health Insurance Fund, Stara Zagora, Bulgaria
}

\begin{abstract}
Child and maternal health are the priority for every developed society. The purpose of this study is to present the principles and methods of financing health promotion and prevention activities for child and maternal health in Bulgaria general practice in the field of child and maternal health, at the level of Primary Health Care in Republic of Bulgaria. Document review of scientific papers, publications of World Health Organization, and normative documents devoted to the Bulgarian Health Care System was carried out. Here are presented the characteristics of the health promotion and prevention activities in Republic of Bulgaria. They are discussed on the basis of the on the basis of compulsory health insurance. The mechanism of Primary Health Care financing is based on the provisions of the National Framework Contract. The main purchaser of health services is the National Health Insurance Fund. The financing model incorporates the following financial components the capitataion and for service - financing of certain health promotion and prevention activity. Questions have been raised about the implementation of effective and accessible best practices for integrated promotion and prevention activities, which give opportunity for complete coverage of mothers and children.
\end{abstract}

Key words: Health promotion, Prevention, Primary Health care, Child and Maternal health, Compulsory Health Insurance.

\section{INTRODUCTION}

The role of Primary Health Care (PHC) in the $21^{\text {st }}$ century has been steadily rising and is in the fundamental position concerning the other elements of the medical care system (1). PHC is reached in a fast and easy way to meet basic health needs of people amid limited health resources (2). The consolidation of PHC provides a reorientation in health care: reorientation from disease to health and prevention; from specialized medical assistance to primary care; reversion from treatment to activity for disease prevention; rerouting to general medicine $(1,3)$. World experience shows that general practice as a form of organization and PHC has greater potential that could be realized, if provided appropriate professional, legal and financial conditions (2, 4). The European Regional Bureau of the World Health Organization (WHO) underlines that the idea of PHC could not be implemented without the participation of doctors in general medicine - general practitioner (GP) $(1,4)$.
The purpose of this study is to present the principles and methods of financing health promotion and prevention activities for child and maternal health in Bulgarian General Practice.

\section{Tasks}

1. To present the core package of general practitioner activities financed by National Health Insurance Fund (NHIF);

2. To present health promotion and prevention activities for Maternal and Child Health programs;

3. To present the financial parameters and flows in the implementation of preventive programs for children and programs for monitoring children and mothers in PHC.

\section{MATERIALS AND METHODS}

Document review of scientific papers, publications of World Health Organization, and normative documents devoted to the Bulgarian Health Care System was carried out. 
Results and Discussion: In Bulgaria, $\mathrm{PHC}$ is entirely based on general practice, with the main role of the general practitioner. GP is the professional who is able to carry out a wide range of activities such as health education, disease prevention, treatment, rehabilitation, palliative care (3). The idea is to confirm and develop these key GP activities to ensure an economically acceptable model of quality health care $(1,3)$.

The main purchaser of health services is the National Health Insurance Fund (NHIF). Social health insurance contributions are calculated at $8 \%$ of monthly income, paid by the insured individuals, their employers, or the state (5). Relations between the NHIF and GPs as health care providers are based on the contract model. The Fund and the Professional Association of Physicians sign the National Framework Contract (NFC), which regulates the format and operational procedures of the compulsory health insurance system. Based on the NFC, GPs sign individual contracts with the regional branches of the Fund $(5,6)$.

The mechanism of PHC financing, respectively GPs is based on the provisions of the NFC. NHIF pays the contracted and performed activity of the PHC contractors (5, 6). GPs as health care providers in PHC, receives monthly a fixed amount for each registered compulsory insured patient - the experience and the activity performed on the relevant elements described in the contract. NHIF entirely finances a package of activities, that are regulated by particular Ordinance of the Ministry of Health for determining the basic package of health activities guaranteed by the budget of the National Health Insurance Fund (7-11). This package includes:

1) Health information activities related to the patient: organization and work schedule of the practice; the contents of the promotional, preventive, prophylactic, diagnostic and treatment and rehabilitation package of the practice; patient rights and obligations.

2) Health Promotion - assessment of the health problems of the patient and family; family planning and contraception.

3) Prevention of diseases and AIDS, infectious and parasitic diseases, addictions, malignancies, mental disorders; Assessment of risk factors for health of the patient, the assessment of harmful habits, leading to health damage, general health risk assessment (e.g., cardiovascular diseases, diabetes, cancer); activities according to national health programs - funded from the budget of the Ministry of Health in accordance with respectful programs; Prophylactic examinations under the Ordinance on prophylactic examinations and periodic follow-up examinations.

4) Follow up clinical examination of persons with conditions under the Ordinance on prophylactic examinations and periodic followup examinations.

5) Control of infectious diseases, according to the requirements of normative documents: Quarantine of infectious disease patients and contact persons; explaining to the patient and contact persons the requirements for health behavior and safety arrangements; immunizations according to the Immunization Calendar approved by the Minister of Health (7).

6) Primary and follow-up examinations; Providing medical assistance in emergencies; Providing medical care at the patient's home; Carrying out manipulations; Performing or appointing clinical laboratory tests, apparatus diagnostic tests; Evaluation of growth and development in children (0 -18); Appointing and monitoring the implementation of hygiene and dietary regime; Performing or appointing clinical laboratory tests, apparatus diagnostic tests.

7) Other activities related to diagnosis and treatment; Referral for consultation; Referral and assistance for hospitalization.

8) Activities in medical expertise - Prenatal medical expertise; Pre-employment expertise; Expertise on temporary incapacity for work and ect.

9) Out-of-hours care. The GP provides a continuous urgent continuous round the clock access to consultation by telephone at clinical setting or at home.

The financing model of PHC incorporates the following financial components: for registered patient, the capitataion and for service financing of certain health promotion and prevention activity (6). The capitation is monthly funding for GP based on the number of enrolled patients, in which patients are arbitrarily chosen to register $(7,10)$. The payment for capitation is defined only by the age of the compulsory health insured person (CHIP) (6). By 2017 , the payment for capitation is presented at Table 1 comparing 2 periods:

Table 1. Payment for capitation for 2006 and 2017.

\begin{tabular}{|l|c|c|}
\hline \multicolumn{1}{|c|}{ Age group } & NFC -2006 year & NFC - 2017 year. \\
\hline Up to 18 years & $1,00 \mathrm{lv}$. & $1,37 \mathrm{lv}$. \\
\hline 18-65 years & $0,72 \mathrm{lv}$. & $1,05 \mathrm{lv}$. \\
\hline Over 65 years & $1,09 \mathrm{lv}$. & $1,47 \mathrm{lv}$. \\
\hline
\end{tabular}


Financing for service rendered -these services are related to prevention and monitoring of the insured persons. GPs receive monthly payment for health promotion and preventive activity. It is paid differentially according to the age of the children, presented at the Table 2.

Table 2. Payment for services (monthly payment for health promotion and prevention activity by age of children)

\begin{tabular}{|c|c|}
\hline $\begin{array}{c}\text { Age group of children } \\
\text { from Patient List of GP`s }\end{array}$ & NFC - 2017 year \\
\hline 0- 1 years & $10,50 \mathrm{lv}$ \\
\hline 1-2 years & $9,50 \mathrm{lv}$ \\
\hline 2-7 years & $9,50 \mathrm{lv}$ \\
\hline 7-18 years & $9,00 \mathrm{lv}$ \\
\hline
\end{tabular}

The health services in which the observation of the children up to 18 years of age is regulated by NHIF (Appendix 13), are defined by age group with a certain number and periodicity.

Until the child reaches one month, the GP is obliged to make two examinations of the newborn, with a recommended interval of 7 to 14 days, with anamnesis and detailed status and advice for newborn and promoting breastfeeding. Up to 1 year old of the child, every mounth performs a child's health examination: anamnesis and detailed status, measuring height, weight and assessment of psychological development. A total assessment of vision and hearing is done twice for the first year of the child's life, as well as a clinical examination for hip dysplasia with risk assessment of dysplasia.

NHIF funds four times a year, over a period of no less than 2 months, any routine study of the child's health status from 1 to 2 years of age, which includes a history and detailed status, measuring height and weight, breast circumference, assessment of mental development.

In the period of 2 to 7 years, a rapid growth examination is performed two times a year through a period no less than 4 months with a history and detailed status, measuring height and weight, breast circumference; clinical laboratory study of Hemoglobin, Red Blood cells, number of leukocytes and other - once at the age of three $(9,10)$.

From 7 to 18 years old of the child, GP assesses the developmental status of the adolescent (a state of puberty development) and routine general health check of others specified subgroups of the population once a year, GP measures height and weight, breast circumference, measured arterial pressure, assesses the physical development, study of visual acuity (approximately), color sensitivity; deviations in the development of the locomotor system and examines urine for proteinuria.
Throughout the development period of the child up to 18 years of age, GP places mandatory and recommended vaccines. The work of GP in return with immune prophylaxis is carried out in accordance to regulation on immunizations in Republic of Bulgaria and according the Immunization Calendar. Each immune-prevention activity is separately funded by the NHIF at the price - 4,50 lv., with the possibility of 2 recommended vaccines (against cervix cancer and rotaviruses), which are also paid by NHIF at prices $-4,00 \mathrm{lv}$. $(9,10)$.

Under the Maternal Health Program, GP's activities are related to the observation only of a normal pregnancy. By the type activities are the following: 1 . The history of risk factors (age, accompanying diseases, complications of previous pregnancies, bad habits, professional and others risk factors). 2. Measurement of blood pressure 3. Anthropometry (growth, weight, external pelvimetry). 4. Ginecological status. 5. Fetal heart activity. Each activity has a certain frequency according to the NHIF Appendix 13. GP also carries out routine follow-up surveillance with an assessment of the mental status; measuring blood pressure; follow-up of uterine involution and bleeding from the genitals; manual survey of dairy glands; follow-up lactation and Promotion of breastfeeding; proper nutrition, hygienic care for breasts and genitals (10). Two examinations are funded: until the seventh day and after the thirtieth day of birth. The price for enamination by the Maternal Health Program is $7 \mathrm{lv}$. There is a tendency for the reduction of the health services under this program by GPs $(12,13,14,16)$.

For the Periodic follow-up examinations of persons with one or more diseases the GP is paid for patients divided in three groups according to the number of diseases: a person with one disease - 9,50 lv.; with two diseases $11,40 \mathrm{lv}$., for three and more diseases $-13,30$ lv. Prophylactic examinations of patients, over 
18 years of age $-12 \mathrm{lv}$ and for immunizations of persons over 18 years of age $-4,5 \mathrm{olv}$.

The adopted model of financing for the PHC providers is structured mixed on a capitation and payment for services. The capitation provides guaranteed funding for GPs, for the provision of medical services to those enrolled in the patient list. In recent years, the amount of money that arrive at primary care establishments for health promotion and prevention activities has increased. There is tendency to reduce the relative share of capitation payments and an increase for activities $(13,14,15)$. Preventive examinations of pregnant women and children are extremely important for proper progression of pregnancy and for protection of the health and life of the fetus, mother and children $(12,13,15,16)$. At the same time in recent years there have been changes in specialized medical care, for these two groups, the pregnant woman can choose to carry out reviews of maternity healthcare program. Respectively, the proportion of GPs implementing this program is very low. In children they are implemented by GPs, as desired by the parent women, children under the age of 1, may be performed by a pediatrician $(15,16,17,18)$. GP is a central figure that can guarantee access to these preventive activities. Focus is inappropriate to change to other levels of the health system (13, $16,17)$.

\section{CONCLUSION}

The financial efficiency of the health system is directly related to the promotion activities of the healthy life, active prevention and screening of socially significant diseases. The principles and methods of financing GPs could be closely related to the quantity and quality of the health service provided, to act an incentive their motivation to make them accessible and quality health-promotion and prophylactic activity in the field of maternal and child healthcare. Real health benefits for mothers and children can be achieve at an affordable price, most notably in primary health care, by investing in health promotion and disease prevention.

*This article is written under Project No 11,Competition session of Medical Faculty, Trakia University, 2017 "Promotional and prevention activities for maternal and child health in primary outpatient medical care: current assessments and perspectives".

\section{REFERENCES}

1. World Health Organization, The World Health Report 2008: Primary Health Care -
Now More than Ever. Geneva, Switzerland: World Health Organization, 2008, available on: http://www.who.int

2. Organisation for Economic Co-operation and Development \& European Commission (OECD \& EC) available on: http://www.oecd.org/ireland/44592

3. WONCA Europe, The European Definitions of The Key Features of the Discipline of General Practice and The Role of the General Practitioner, 2011 Edition, available on: http://www.woncaeurope.org/sites/default/f iles/documents/Definition

4. Opinion of the European Economic and Social Committee on The human resource in the health sector in Europe COM (2008) 725 available at" COM (2008) 725, available on": http://eurlex.europa.eu/LexUriServ/.

5. Dimova A, Rohova M, Moutafova E, Atanasova E, Koeva S, Panteli D, van Ginneken E. Bulgaria: Health system review. Health Systems in Transition, 2012, 14(3):1-186.

6. Health Insurance Act, available on http://www.nhif.bg/web/guest/1421

7. Salchev P., Primary Health Care in Bulgaria - facts and analyses, Open Society Institute, Sofia, 2011.

8. National Framework Contract 2017, Promulgated, State Gazette No. 70/19.06.1998,amended and supplemented, SG No.113/28.12.2007, available on: http://www.nhif.bg/web/guest/1421

9. Ordinance № 2 of 25.03 .2016 for determining the basic package of health activities guaranteed by the budget of the National Health Insurance Fund Issued by the Minister of Health State Gazette No 9.05.2017. available on: http://www.nhif.bg/web/guest/1421

10. Applied 13 of NHIF" available on: "http://www.nhif.bg/web/guest/1421

11. Ordinance on prophylactic examinations and dispensarisation № 15/12.05.2005. available on: http://www.mh.government.bg/bg/normativ ni-aktove/naredbi/

12. Marinova J., K. Peeva, G. Veleva, D. Mihaylova, Management of Health Priorities in the General Practitioner's Practice - Results of Empirical Study, Social Medicine 3, 2002: 35-37.

13. Marinova Juliana, Aleksandra Zdraveska, Boryana Parashkevova, Unintended Pregnancy Prevention In General Practice: Attitudes Of General Practitioners With Practices In A Big City, Southeast 
European Medical Forum (SEEMF), Slovenia Medical Association: Fourth International Medical Congress, 11-15 September, 2013 - Portoroz, Slovenia, Book of abstracts: 118-119.

14. Parashkevova B., General Practitioner in the Health System - History, Development and Perspectives, Stara Zagora, 2016, p 132.

15. Zahariev B., L. Yadkova, L. Peneva, I. Yordanov The Welfare of Children in Early Childhood in Bulgaria, Collection of Reports, Open Society Institute - Sofia, 2010.

16. Aleksandra Zdraveska, Boryana Parashkevova, Juliana Marinova, preventive activities for Women's
Reproductive Health: Attitudes Of General Practitioners' With Practices In a Big City, 23rd Simposium of General Practitioners Family Medicine with International Participation, 18-20 October, 2014, Scopje, Republic of Macedonia, Book of abstracts: 121.

17. Petrova G, Development of the prophylactic field in child healthcare, "INTERDISCIPLINARY IDEA IN ACTION", Book of articles, Sofia 2013: 268-271

18. Paskaleva R., A. Uzunova, S. Radev, Early Diagnosis And Prevention Of Spinal Deformities In Kindergarten. Activities in Physical Education and Sport, 2015, Vol. 5, No. 2, pp. 163-166. 